\title{
Special Issue on Psychology of Prosocial Behavior
}

\section{F. Richard Ferraro ${ }^{1}$}

Published online: 17 July 2019

(C) Springer Science+Business Media, LLC, part of Springer Nature 2019

It is with great pleasure that I announce another Special Issue of Current Psychology. Manpal Bhogal (University of Wolverhampton) and Daniel Farrelly (Worcester University) have put together this Special Issue on a timely topic if ever there was one. It feels like we live in a society that is nearly devoid of prosocial behavior, defined as helping, sharing, donating, cooperating across and within society. Perhaps psychology can be used for good, outlining and advancing prosocial behavior. Articles in this Special Issue run the gamut of prosocial behavior activities, including chivalry, kindness, generosity. Mate choice, altruism, trust, social networks, attractiveness, and emotional, cultural and cognitive variables. As mentioned this Special Issue is timely on a number of fronts and it is our hope and expectation that this Special Issue, like previous ones, will start a dialogue and debate about why it is so critical for prosocial behavior (however defined) to be used for positive social interaction, building and rebuilding of social and cultural relationships and how to advance the notion that cooperating is good. I hope you enjoy this Special Issue.

Pulisher's note Springer Nature remains neutral with regard to jurisdictional claims in published maps and institutional affiliations
F. Richard Ferraro

f.ferraro@und.edu; https://www.editorialmanager.com/cups

1 Department of Psychology, University of North Dakota, 2921

Columbia Hall, 501 N. Columbia Rd., Stop 8380, Grand

Forks, ND 58202-8380, USA 